\title{
Electron density profiles probed by radio occultation of FORMOSAT-7/COSMIC-2 at 520 and $800 \mathrm{~km}$ altitude
}

\author{
J. Y. Liu ${ }^{1,2}$, C. Y. Lin ${ }^{1}$, and H. F. Tsai ${ }^{3}$ \\ ${ }^{1}$ Institute of Space Science, National Central University, Taoyuan, Taiwan \\ ${ }^{2}$ Center for Space and Remote Sensing Research, National Central University, Taoyuan, Taiwan \\ ${ }^{3}$ Department of Earth Sciences, National Cheng Kung University, Tainan, Taiwan \\ Correspondence to: J. Y. Liu (jyliu@ jupiter.ss.ncu.edu.tw)
}

Received: 1 November 2014 - Published in Atmos. Meas. Tech. Discuss.: 4 February 2015

Revised: 28 June 2015 - Accepted: 14 July 2015 - Published: 3 August 2015

\begin{abstract}
The FORMOSAT-7/COSMIC-2 (F7/C2) will ultimately place 12 satellites in orbit with two launches with 24 $28.5^{\circ}$ inclination and $520-550 \mathrm{~km}$ altitude in 2016 and with $72^{\circ}$ inclination and $720-750 \mathrm{~km}$ altitude in 2018 . It would be very useful for the community to construct the global three-dimensional electron density structure by simultaneously combining the two launch observations for studying ionospheric structure and dynamics. However, to properly construct the global electron density structure, it is essential to know and evaluate differences between the ionospheric electron densities probed by the two launches. To mimic the F7/C2 observations, we examine the electron density probed at the two satellite altitudes 500 and $800 \mathrm{~km}$ by means of FORMOSAT-3/COSMIC (F3/C) observations at the parking orbit $500 \mathrm{~km}$ altitude and mission orbit $800 \mathrm{~km}$ altitude, as well as a corresponding observing system simulation experiment (OSSE). Observation and OSSE results show that the sounding geometries by satellite orbiting at 500 and $800 \mathrm{~km}$ altitudes can cause the overall differences in the electron density, the F2 peak electron density, and the F2 peak height of about 18-24, 12-28\%, and 7-19 km, respectively. Results confirm that the discrepancies mainly result from the sounding geometry and the grid (contour) bias of the electron density.
\end{abstract}

\section{Introduction}

On 15 April 2006, six microsatellites of FORMOSAT3/COSMIC (F3/C) were launched to the parking orbit of about $516 \mathrm{~km}$ altitude and subsequently lifted to the mis- sion orbit at about $800 \mathrm{~km}$, both with an inclination of $72^{\circ}$. Each microsatellite has been receiving GPS signals to carry out radio occultation (RO), which yields abundant information about neutral atmospheric temperature and moisture as well as space weather estimates of slant total electron content (TEC), electron density profiles, and an amplitude scintillation index, S4 (Schreiner et al., 2007). The Abel inversion (cf. Hajj and Romans, 1998) has been employed to invert the electron density from the RO TEC. With the success of F3/C, the United States and Taiwan are moving forward with a follow-on RO mission named FORMOSAT-7/COSMIC2 (F7/C2), which will ultimately place 12 satellites in orbit with two launches with $24-28.5^{\circ}$ inclination and 520 $550 \mathrm{~km}$ altitude in 2016 and with $72^{\circ}$ inclination and 720 $750 \mathrm{~km}$ altitude in 2018 (Lee et al., 2013; Yue et al., 2014; Yen, 2015). Scientists find that the local spherical symmetry assumption in the standard (Abel) RO inversion processes results in systemic biases, especially the EIA (equatorial ionization anomaly) at low latitudes, where the horizontal gradient is most significant (cf. Liu et al., 2010b). Lei et al. (2007) indicated that to conduct the Abel inversion, the electron density at the satellite altitude should be assumed. Yue et al. (2011) conducted simulations based on F3/C observations using NeQuick model and found that the solar activity and the satellite orbit altitude variations do not influence the ratio of the successfully retrieved electron density profiles to the observed occultation events and the relative Abel inversion error of the electron density as well. They also show that different orbit electron density derivation methods have no essential influence on the Abel retrieved electron density. Their statistical results indicate that the orbit electron 


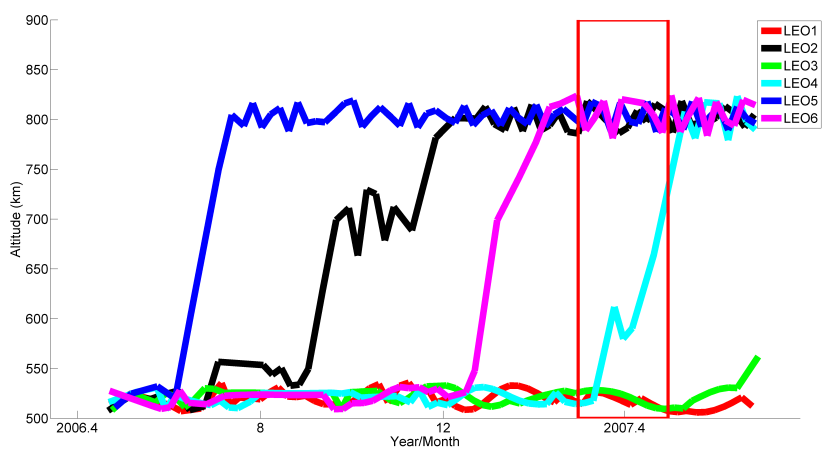

Figure 1. The altitude of each F3/C microsatellite from launch to middle of 2007. The red box indicates the time period of the study.

density estimation error has no obvious dependency on either the solar activity or the orbit altitude. It is essential to know and evaluate the difference between the two electron density profiles retrieved from the sounding geometries of satellites orbiting at 500 and $800 \mathrm{~km}$ altitudes for combining the two electron density profiles to construct the global three-dimensional electron density structure. In this paper, we examine the effect of satellite altitude on the Abel inversion by firstly comparing the electron density profiles ranging from 100 to $500 \mathrm{~km}$ altitude observed by satellites at 500 and $800 \mathrm{~km}$ altitude and their differences during the early F3/C mission period. Observing system simulation experiments (OSSEs) by means of the standard F3/C Abel inversion are used to produce above the observation. Cross comparisons among the observation and the OSSE shall have a better understanding on the electron density profiles observed at 520 550 and $720-750 \mathrm{~km}$ altitude for the upcoming F7/C2 mission during both solar minimum and solar maximum.

\section{F3/C electron density profiles observed at 500 and $800 \mathrm{~km}$ altitude}

One half of F3/C satellites were orbiting at the parking orbit $500 \mathrm{~km}$ altitude and the other half at the mission orbit $800 \mathrm{~km}$ altitude in March and April 2007 (Fig. 1). The satellites at 500 and $800 \mathrm{~km}$ altitude probed 5812 and 5425 electron density profiles during 12:00-14:00 UT in March and April of 2007. During the study period, satellite LEO4 was transferred from 500 to $800 \mathrm{~km}$ altitude, and therefore its electron density profiles probed below and above $600 \mathrm{~km}$ altitude are classified into 500 and $800 \mathrm{~km}$ altitude, respectively. The electron density profiles are gridded with $5^{\circ}$ in latitude, $20^{\circ}$ in longitude, and $5 \mathrm{~km}$ in altitude and the median of the electron density in each grid is computed. Figure 2 displays that the global electron density $N$, F2 peak electron density $N m \mathrm{~F} 2$, and height $h m \mathrm{~F} 2$ observed at the 500 and $800 \mathrm{~km}$ satellite altitude, and their difference. The longitude cuts in $-120,-60,0,60$, and $120^{\circ}$ stand for the electron density at 05:00, 09:00, 13:00, 17:00, and 21:00 LT, respectively. It can be seen that structures of the electron density observed from $500 \mathrm{~km}$ satellite altitude $\left(N_{500}\right)$ and from $800 \mathrm{~km}$ satellite altitude $\left(N_{800}\right)$ at 09:00, 13:00, 17:00, and 21:00 LT are similar, respectively. Since the accuracy in the lower ionosphere is relatively low, we focus on the electron density in the topside ionosphere (i.e., the region above the F2 peak). It can be seen that the $N_{500}$ is slightly greater (less) than $N_{800}$ in the equatorial (off-equator) ionosphere, while $N_{500}$ is slightly weaker than $N_{800}$ in the South Pole region at 09:00 LT. $N_{500}$ is greater than $N_{800}$ in the EIA region at 13:00 LT; $N_{500}$ is weaker (greater) than $N_{800}$ in the northern (southern) EIA region at 17:00 LT; and $N_{500}$ is weaker than $N_{800}$ in the southern EIA region at 21:00 LT. The difference between the two electron densities $N_{500}-N_{800}$ generally agrees with the above comparisons and also reveals that $N_{500}$ is greater than $N_{800}$ in the northern EIA at 21:00 LT. The F2 peak electron density $N m \mathrm{~F} 2$ observed from 500 and $800 \mathrm{~km}$ altitude $(N m \mathrm{~F} 2500$ and $N m \mathrm{~F} 2_{800}$ ) displays that the two $N m \mathrm{~F} 2$ s yield similar patterns and $N m \mathrm{~F} 2_{800}$ is generally greater than $N m \mathrm{~F} 2_{500}$ in the northern EIA area. However, due to the data locations being different, the difference of $N m \mathrm{~F} 2_{500}-N m \mathrm{~F} 2_{800}$ is difficult to identify. The $\mathrm{F} 2$ peak height $h m \mathrm{~F} 2$ probed from 500 and $800 \mathrm{~km}$ satellite altitude $(h m \mathrm{~F} 2500$ and $h m \mathrm{~F} 2800)$ as well as their difference illustrated that the two $h m \mathrm{~F} 2 \mathrm{~s}$ are general similar in the low and mid-latitudes. In short, the F3/C electron densities observed from 500 and $800 \mathrm{~km}$ satellite altitude are qualitatively similar.

\section{Abel OSSE}

To carry out Abel OSSEs, we first insert realistic F3/C RO ray path geometries into the corresponding ionosphere computed by the International Reference Ionosphere (IRI)-2007 (Bilitza and Reinisch, 2008) to simulate the total electron content (TEC), and then apply the Abel inversion routine of CDAAC (COSMIC Data Analysis and Archival Center) to derive electron density profiles. Figure 3 displays the truth of the electron density, the $N m \mathrm{~F} 2$, and $h m \mathrm{~F} 2$ computed by IRI. The truth electron density shows that the EIA is greater in the Northern Hemisphere than that in the Southern Hemisphere, which can be found in $N m \mathrm{~F} 2$ distributions. The daytime $h m \mathrm{~F} 2$ reaches the highest altitude in the EIA region, while $h m \mathrm{~F} 2$ at mid- and high latitudes in nighttime is higher than those in daytime. Figure 4 depicts OSSE electron density, $N m \mathrm{~F} 2$, and $h m \mathrm{~F} 2$ observed by satellites at 500 and $800 \mathrm{~km}$ altitude, and their difference. It can be seen that $N_{500}$ is slightly weaker than $N_{800}$ in the South Pole region at 09:00 LT; $N_{500}$ is greater than $N_{800}$ in the EIA region at 1300 and 17:00 LT; and $N_{500}$ is weaker than $N_{800}$ in the southern EIA region at 21:00 LT. Note that both $N_{500}$ and $N_{800}$ in EIA are greater in the north than those in the south obtained by the Abel OSSE, which agree with the truth, respectively. It should be mentioned that the difference between $N_{500}$ and $N_{800}$ of the F3/C observation and that of the Abel OSSE yield similar features. The OSSE reveals that the $N m \mathrm{~F} 2500$ is slightly less 

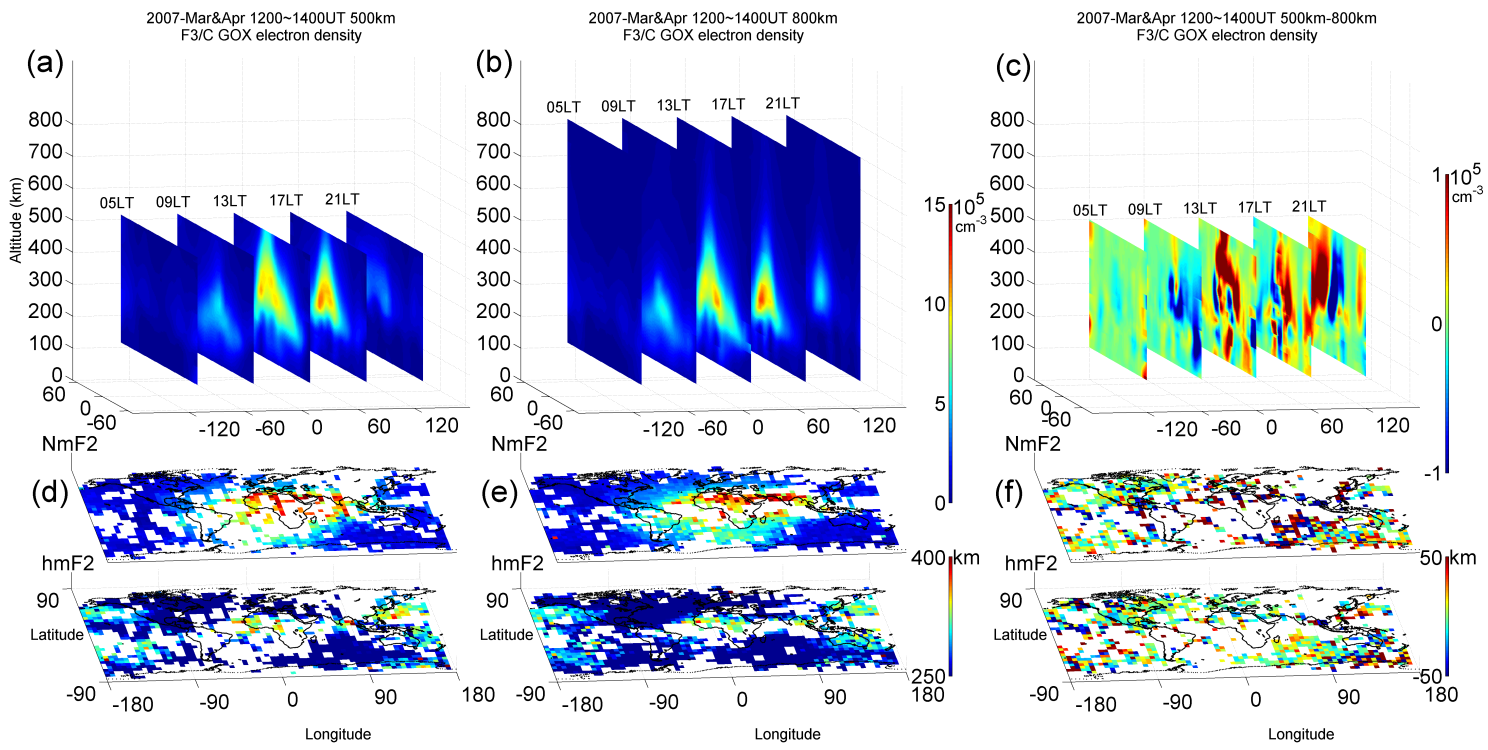

Figure 2. The F3/C electron density, $N m \mathrm{~F} 2$, and $h m \mathrm{~F} 2$ observed from 500 and $800 \mathrm{~km}$ altitude satellites, and their difference during 12:0014:00 UT in March and April of 2007. (a) F3/C electron density observed from $500 \mathrm{~km}$ altitude, (b) F3/C electron density observed from $800 \mathrm{~km}$ altitude, and (c) their difference. (d) F3/C $N m \mathrm{~F} 2$ and $h m \mathrm{~F} 2$ observed from $500 \mathrm{~km}$ altitude, (e) F3/C $N m \mathrm{~F} 2$ and $h m \mathrm{~F} 2 \mathrm{observed}$ from $800 \mathrm{~km}$ altitude, and (f) their difference.

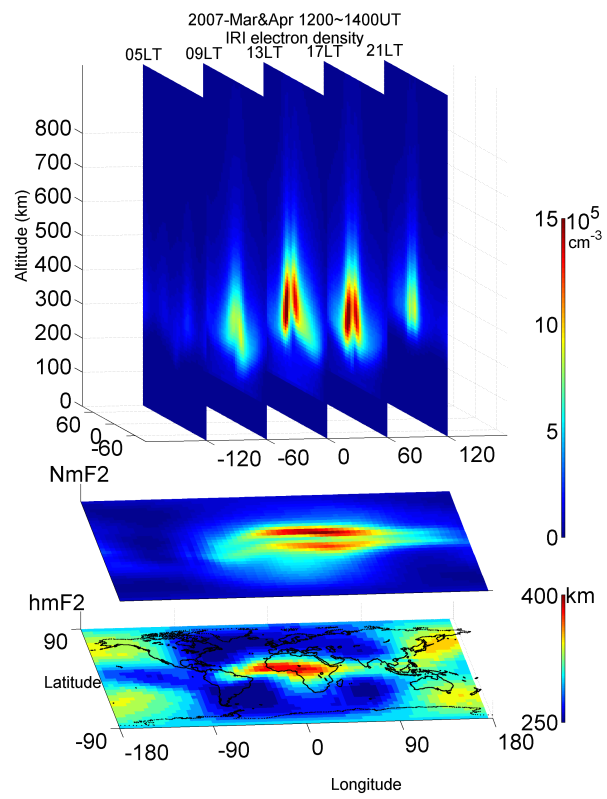

Figure 3. The OSSE truth. The median of IRI output obtained from 12:00-14:00 UT in March and April of 2007. The electron density distribution, $N m \mathrm{~F} 2$, and $h m \mathrm{~F} 2$ are shown from up to down.

than $N m \mathrm{~F} 2800$ in the northern EIA region; however the corresponding difference of $N m \mathrm{~F} 2500-\mathrm{NmF} 2800$ is rather complex. On the other hand, $h m \mathrm{~F} 2500$ and $h m \mathrm{~F} 2800$ in the low and midlatitudes are generally similar.
We further find whether there is any systematic error due to the different satellite altitudes of 500 and $800 \mathrm{~km}$ by subtracting the results of the Abel OSSE from the IRI truth. Similar patterns shown in Fig. 5a and 5b suggest the Abel inversion could result in systematic error in the EIA region, where both $N_{500}$ and $N_{800}$ underestimate the electron density in the EIA crests but overestimate in the magnetic equator and/or poleward sides of the EIA crests. Again, we examine the differences of the topside ionosphere retrieved between satellites at 500 and $800 \mathrm{~km}$ altitudes (Fig. 5c). The underestimation of $N_{500}$ is more severe than that of $N_{800}$ above F2 peak in the EIA region at $1300 \mathrm{LT}$ and $N_{500}$ is not as severe as $N_{800}$ above F2 peak in the EIA region at 09:00 and 17:00 LT. On the other hand, the error patterns of $N m \mathrm{~F} 2500$ and $N m \mathrm{~F}_{800}$ are similar, which underestimate in the two EIA crests but overestimate in their poleward sides. It is interesting to find that the errors of both $h m \mathrm{~F} 2500$ and $h m \mathrm{~F} 2_{800}$ are similar, which show error of $h m \mathrm{~F} 2$ being small globally.

\section{Discussion and conclusion}

The F3/C observation and OSSE show that the electron density, $N m \mathrm{~F} 2$, and $h m \mathrm{~F} 2$ probed at 500 and $800 \mathrm{~km}$ altitude are similar (Figs. $2 \mathrm{a}$ and $\mathrm{b}$ and $4 \mathrm{a}$ and $\mathrm{b}$ ). Although the real and IRI ionospheres might be different, the differences $N_{500}$ $N_{800}$ shown in Figs. $2 \mathrm{c}$ and $4 \mathrm{c}$ are somewhat similar, especially in the topside ionosphere. Table 1 further reveals that the overall difference $N_{500}-N_{800}$ of the F3/C observation and OSSE are $23.5 \pm 35.1$ and $18.6 \pm 30.9 \%$. The overall difference $N_{500}-N_{800}$ could result from the observation data 
Table 1. The differences of $N, N m \mathrm{~F} 2$, and $h m \mathrm{~F} 2$ observed at 500 and $800 \mathrm{~km}$ altitude.

\begin{tabular}{rcccc}
\hline & $\begin{array}{c}\mathrm{F} 3 / \mathrm{C} \\
500-800 \mathrm{~km}\end{array}$ & $\begin{array}{c}\text { Abel OSSE } \\
500-800 \mathrm{~km}\end{array}$ & $\begin{array}{c}\text { Abel OSSE } \\
500 \mathrm{~km}-\text { truth }\end{array}$ & $\begin{array}{c}\text { Abel OSSE } \\
800 \mathrm{~km}-\text { truth }\end{array}$ \\
\hline$\Delta N(\%)$ Solar min & $23.5 \pm 35.1$ & $18.6 \pm 30.9$ & $16.8 \pm 33.4$ & $17.4 \pm 33.7$ \\
Solar max & & $19.1 \pm 31.3$ & $19.1 \pm 36.9$ & $18.4 \pm 36.1$ \\
$\Delta N m \mathrm{~F} 2(\%)$ Solar min & $28.0 \pm 39.1$ & $14.1 \pm 21.3$ & $7.4 \pm 9.7$ & $7.6 \pm 10.2$ \\
Solar max & & $11.9 \pm 16.6$ & $6.3 \pm 8.8$ & $6.2 \pm 8.2$ \\
$\Delta h m \mathrm{~F} 2(\mathrm{~km})$ Solar min & $19.3 \pm 27.3$ & $7.4 \pm 10.4$ & $3.7 \pm 5.8$ & $3.4 \pm 5.3$ \\
Solar max & & $8.7 \pm 11.6$ & $4.8 \pm 7.2$ & $4.2 \pm 6.2$ \\
\hline
\end{tabular}
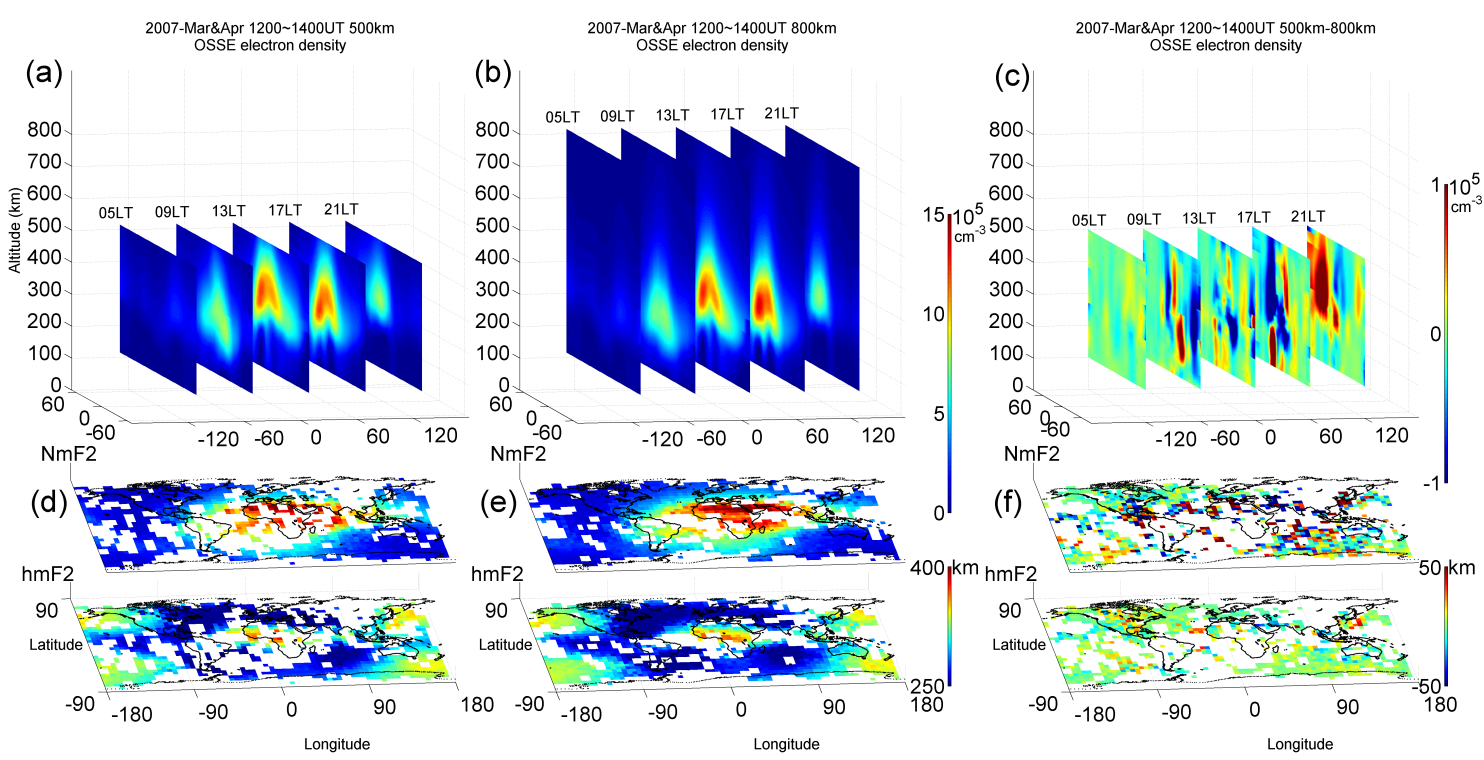

Figure 4. The Abel inversion OSSE electron density, $N m \mathrm{~F} 2$, and $h m \mathrm{~F} 2$ observed from 500 and $800 \mathrm{~km}$ altitude satellites, and their difference during 12:00-14:00 UT in March and April of 2007. (a) OSSE electron density observed from $500 \mathrm{~km}$ altitude, (b) OSSE electron density observed from $800 \mathrm{~km}$ altitude, and (c) their difference. (d) OSSE $N m \mathrm{~F} 2$ and $h m \mathrm{~F} 2$ observed from $500 \mathrm{~km}$ altitude, (e) OSSE $N m \mathrm{~F} 2$ and $h m \mathrm{~F} 2$ observed from $800 \mathrm{~km}$ altitude, and (f) their difference.

cumulated in the two study months, the RO tangent points from the two different satellite orbits, and the grid bias of the electron density of $N_{500}$ and $N_{800}$. It can be seen that the patterns in Figs. $4 \mathrm{c}$ and $5 \mathrm{c}$ are different, although both represent the differences in the electron density of $N_{500}-N_{800}$. This discrepancy might mainly result from the grid (contour) process, since the difference of $N_{500}-N_{800}$ in Fig. $4 \mathrm{c}$ is obtained by gridding (or contouring) $N_{500}$ and $N_{800}$ separately and then subtracting one from the other, while Fig. $5 \mathrm{c}$ is derived by subtracting the truth from OSSE $N_{800}$ and the truth from the OSSE $N_{500}$ point by point, then carrying out the contour process on each error, separately, and finally subtracting the $N_{800}$ contoured error from the $N_{500}$ one. Nevertheless, Figs. $4 \mathrm{c}$ and $5 \mathrm{c}$ strongly suggest that the sounding geometry and the grid (contour) bias of the electron density are the major sources causing the differences in the electron density of $N_{500}-N_{800}$. On the other hand, the patterns in $N m \mathrm{~F} 2_{500}$ and $N m \mathrm{~F} 2_{800}$ as well as those in $h m \mathrm{~F} 2500$ and $h m \mathrm{~F} 2800$ of the $\mathrm{F} 3 / \mathrm{C}$ observation and OSSE are some- what similar (Figs. $2 \mathrm{~d}$ and e and $4 \mathrm{~d}$ and e). Table 1 shows that during the solar minimum of 2007, the overall differences $N m \mathrm{~F} 22_{500}-N m \mathrm{~F} 2_{800}\left(h m \mathrm{~F} 2_{500}-h m \mathrm{~F} 2_{800}\right)$ of the $\mathrm{F} 3 / \mathrm{C}$ observation and OSSE are $28.0 \pm 39.1$ and $14.1 \pm 21.3 \%$ $(19.3 \pm 27.3$ and $7.4 \pm 10.4 \mathrm{~km})$, respectively. Nevertheless, the pattern similarities and the difference means being less than $20 \%$ imply that the Abel inversion routine of CDAAC can be applied to reasonably derive electron density profiles by the RO TEC probed at $500 \mathrm{~km}$ satellite altitude. The OSSE error of the Abel inversion reveals that the topside ionospheric electron density at EIA region has been underestimated (Fig. 5). Moreover, we want to see whether the results hold true for the solar maximum when $500 \mathrm{~km}$ is much closer to the $\mathrm{F}$ region peak altitude. We also conduct OSSEs during the solar maximum of 2002. It is found that the standard deviation in the solar maximum is similar to the corresponding one in the solar minimum, which confirms that the results hold true even for the solar maximum. 

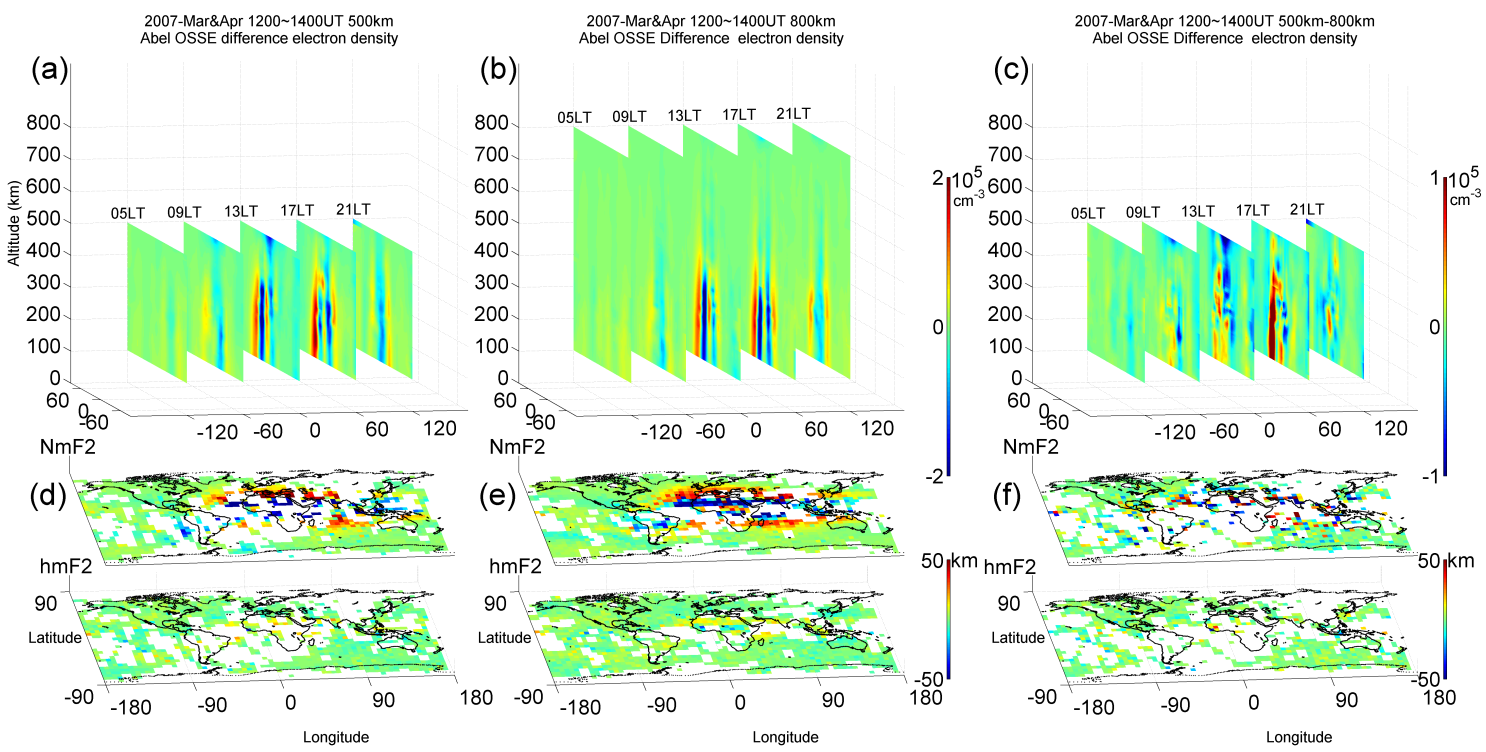

Figure 5. The Abel inversion OSSE error (OSSE result-truth) electron density, $N m \mathrm{~F} 2$, and $h m \mathrm{~F} 2$ observed from 500 and $800 \mathrm{~km}$ altitude satellites, and their difference during 12:00-14:00 UT in March and April of 2007. (a) OSSE electron density error observed from 500 km altitude, (b) OSSE electron density error observed from $800 \mathrm{~km}$ altitude, and (c) their difference. (d) OSSE $N m \mathrm{~F} 2$ and $h m \mathrm{~F} 2 \mathrm{error}$ observed from $500 \mathrm{~km}$ altitude, (e) OSSE $N m \mathrm{~F} 2$ and $h m \mathrm{~F} 2$ error observed from $800 \mathrm{~km}$ altitude, and (f) their difference.
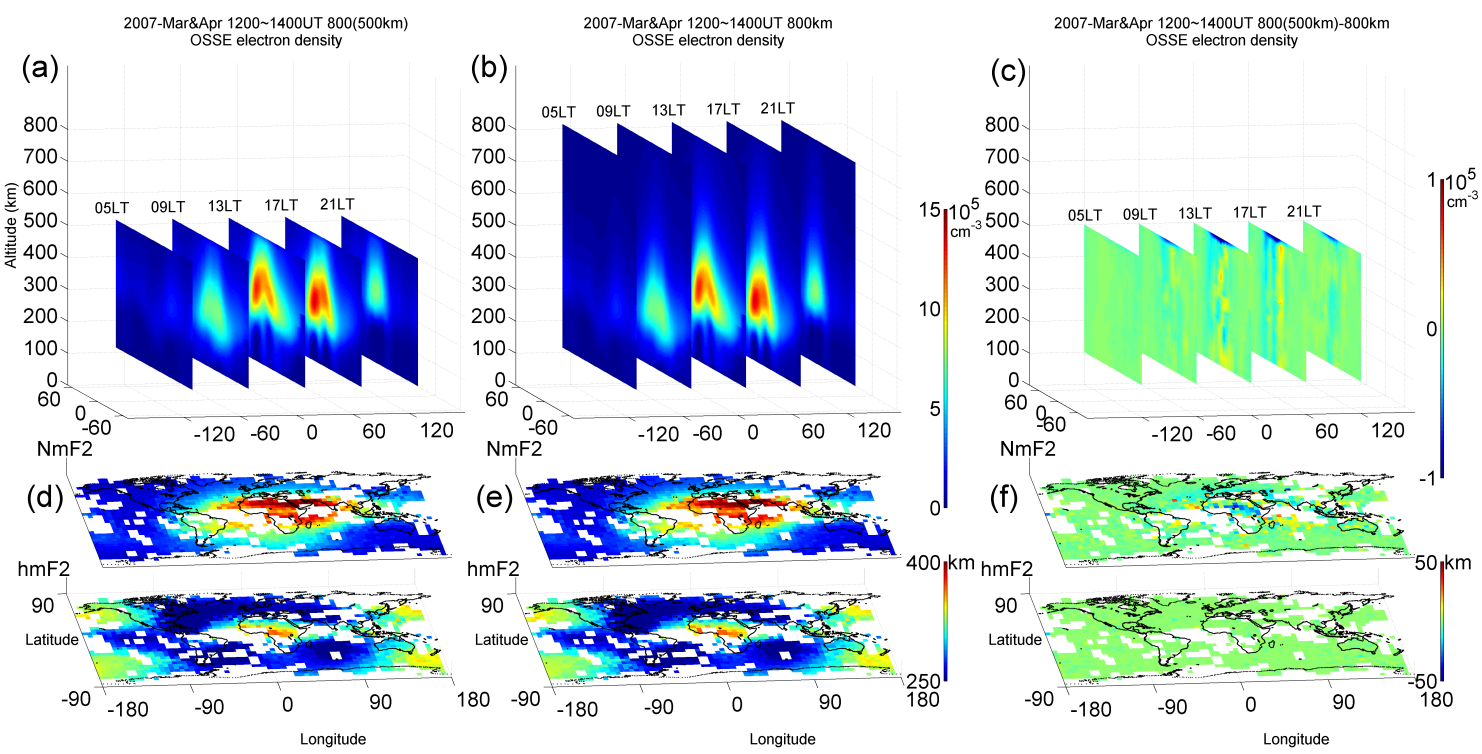

Figure 6. The Abel inversion OSSE electron density, $N m \mathrm{~F} 2$, and $h m \mathrm{~F} 2$ observed from 500 and $800 \mathrm{~km}$ altitude satellites, whose sounding geometries are identical, and their difference during 12:00-14:00 UT in March and April of 2007. (a) OSSE electron density observed from 800 shifted to $500 \mathrm{~km}$ altitude, (b) OSSE electron density observed from $800 \mathrm{~km}$ altitude, and (c) their difference. (d) OSSE $N m$ F2 and $h m F 2$ observed from 800 shifted to $500 \mathrm{~km}$ altitude, (e) OSSE $N m \mathrm{~F} 2$ and $h m \mathrm{~F} 2$ observed from $800 \mathrm{~km}$ altitude, and (f) their difference.

Yue et al. (2011) carry out simulations based on F3/C observations using NeQuick model and indicate that the solar activity and the satellite orbit altitude variations will not influence the ratio of the successfully retrieved electron density profiles to the observed occultation events and the relative Abel inversion error of the electron density as well. They also find that in comparing them to the retrieval error caused by the spherical symmetry assumption, the changes in solar activity and orbit altitude have a relatively small influence on the retrieval error of $N m \mathrm{~F} 2, h m \mathrm{~F} 2$, and TEC. To validate the above inference we conduct an OSSE by comparing the electron density profiles retrieved from satellites at $800 \mathrm{~km}$ altitude and those from satellites with identical sounding geometries but at $500 \mathrm{~km}$ altitude. Figure 6 shows 
that the electron density profiles retrieved by the satellite at $500 \mathrm{~km}$ tend to be smaller than those at $800 \mathrm{~km}$ altitude in the EIA region but are greater than those in the magnetic equator and/or poleward sides of the EIA crests. These discrepancies result from the spherical symmetry assumption of Abel inversion in the EIA region (Liu et al., 2010a). By contrast, Fig. 4 shows that the electron density profiles retrieved by the satellite at $500 \mathrm{~km}$ are very different from those at $800 \mathrm{~km}$ altitude, especially in the EIA region. This further indicates that differences of the sounding geometry at 500 and $800 \mathrm{~km}$ altitude satellites could significantly influence the retrieved electron density profiles by using Abel inversion. It is known that F7/C2 will be ultimately placed during the first launch of six satellites into orbits with $24-28.5^{\circ}$ inclination and $520-550 \mathrm{~km}$ altitude, and during the second launch of six satellites with $72^{\circ}$ inclination and $720-750 \mathrm{~km}$ altitude. Since the sounding geometries of the two launches are going to be very different, the electron density profiles probed by the two altitudes shall be different. Therefore, one must take care to construct the three-dimensional electron density structure by merging the retrieved electron density profiles of the two launches.

Table 1 displays the OSSE results: the means of the overall differences $N_{500}-N_{800}, N m \mathrm{~F} 2_{500}-N m \mathrm{~F} 2_{800}$, and $h m \mathrm{~F} 2_{500^{-}}$ $h m \mathrm{~F} 2800$ in the solar minimum (maximum) are $18.6(19.1 \%)$, $14.1(11.9 \%)$, and $7.4(8.7 \mathrm{~km})$, respectively. The associated values in the $\mathrm{F} 3 / \mathrm{C}$ observations, $23.5,28.0 \%$, and $19.3 \mathrm{~km}$ are greater than those in the OSSE results. The differences of the observations are constantly larger than those of the OSSEs, which might result from the true ionosphere being more structured than the IRI-simulated ionosphere during the study period. Nevertheless, this suggests that the Abel inversion routine of CDAAC can be employed to reasonably derive electron density profiles from the RO TEC sounded at $520 \mathrm{~km} \mathrm{F7/C2}$ satellite altitude. Therefore, the sounding geometry and the contour process are the major bias for constructing the global three-dimensional electron density structure by merging the retrieved electron density profiles probed by the two F7/C2 launches.

Acknowledgements. This study is supported by the Taiwan Ministry of Science and Technology grant MOST 103-2628-M008-001. The authors gratefully acknowledge the COSMIC Data Analysis and Archival Center (CDAAC) and Taiwan Analysis Center for COSMIC (TACC) for providing the FORMOSAT3/COSMIC data.

Edited by: U. Foelsche

\section{References}

Bilitza, D. and Reinisch, B.: International reference ionosphere 2007: improvements and new parameters, Adv. Space Res., 42, 599-609, doi:10.1016/j.asr.2007.07.048, 2008.

Hajj, G. A. and Romans, L. J.: Ionospheric electron density profiles obtained with the global positioning system: results from the GPS/MET experiment, Radio Sci., 33, 175-190, doi:10.1029/97RS03183, 1998.

Lee, I. T., Tsai, H. F., Liu, J. Y., Lin, C. H., Matsuo, T., and Chang, L. C.: Modeling impact of FORMOSAT-7/COSMIC-2 mission on ionospheric space weather monitoring, J. Geophys. Res.-Space, 118, 6518-6523, doi:10.1002/jgra.50538, 2013.

Lei, J., Syndergaard, S., Burns, A. G., Solomon, S. C., Wang, W., Zeng, Z., Roble, R. G., Wu, Q., Kuo, Y.-H., Holt, J. M., Zhang, S. R., Hysell, D. L., Rodrigues, F. S., and Lin, C. H.: Comparison of COSMIC ionospheric measurements with ground-based observations and model predictions: preliminary results, J. Geophys. Res., 112, A07308, doi:10.1029/2006JA012240, 2007.

Liu, J. Y., Lee, C. C., Yang, J. Y., Chen, C. Y., and Reinisch, B. W., Electron density profiles in the equatorial ionosphere observed by the FORMOSAT-3/COSMIC and a Digisonde at Jicamarca, GPS Solut., 14, 75-81, doi:10.1007/s10291-009-0150-3, 2010a.

Liu, J. Y., Lin, C. Y., Lin, C. H., Tsai, H. F., Solomon, S. C., Sun, Y. Y., Lee, I. T., Schreiner, W. S., and Kuo, Y. H.: Artificial plasma cave in the low-latitude ionosphere results from the radio occultation inversion of the FORMOSAT-3/COSMIC, J. Geophys. Res., 115, A07319, doi:10.1029/2009JA015079, 2010 b.

Schreiner, W., Rocken, C., Sokolovskiy, S., Syndergaard, S., and Hunt, D.: Estimates of the precision of GPS radio occultations from the COSMIC/FORMOSAT-3 mission, Geophys. Res. Lett., 34, L04808, doi:10.1029/2006GL027557, 2007.

Yen, N.: FORMOSAT-7/COSMIC-2 progress update and its launch plan, 4th International Radio Occultation Working Group Workshop, Melbourne, Australia, 2015.

Yue, X., Schreiner, W. S., Rocken, C., and Kuo, Y.-H.: Evaluation of the orbit altitude electron density estimation and its effect on the Abel inversion from radio occultation measurements, Radio Sci., 46, RS1013, doi:10.1029/2010RS004514, 2011.

Yue, X., Schreiner, W. S., Pedatella, N., Anthes, R. A., Mannucci, A. J., Straus, P. R., and Liu, J. Y.: Space weather observations by GNSS radio occultationfrom FORMOSAT- 3/COSMIC to FORMOSAT-7/COSMIC-2, Space Weather, 12, 616621, doi:10.1002/2014SW001133, 2014. 